\title{
The crisis early warning of the quality of supply chain based on rough set\&feature weighted support vector machine
}

\author{
Xiu-lian $\mathrm{Hu}^{\mathrm{a}}$, Dan Liu and Qi Jiang \\ Department of Logistics, Fuzhou University of International Studies and Trade, Fuzhou 350202, Fujian, China
}

\begin{abstract}
A Rough Set\&Feature Weighted Support Vector Machine(RS-FWSVM) model is proposed for the quality of supply chain crisis early-warning,which aims at some problems of the quality of supply chain. This model combines the advantages of the RS and FWSVM, which can get classification per-formances by changing the weights of different linear functions in the feature space. Application process of this model to the crisis early warning of SCQ is researched, which can help enable chain enterprises to identify crises in the process of operations and to predict possible crises.
\end{abstract}

\section{Introduction}

The complicated structure and the global extension of the supply chain have exacerbated the chain instability, not only the supply chain faces more and more risks, but also the supply chain crisis break out repeatedly. All above make the the quality of supply chain crisis early-warning management become an extremely important subject. So enterprises must realize that it is very important to adopt the early-warning management of the crisis of the quality of supply chain,do a good job of warning and preventing the crisis in advance, and then take effective measures to avoid that.

In 1993, Japan's famous supplier of semiconductor materials Sumitomo Chemical plant got exploded, which posed a serious threat to the global supply [1]. The international financial crisis caused by the U.S.subprime crisis in 2009 putted great pressure on enterprises of our country. In 2015, the explosions at Tianjin Port brought the huge impact on global supply chain, which leaded to the electronics industry supply disruptions.

Frequent crisis shows to enterprises that the quality of supply chain crisis is needed. The quality of supply chain crisis early-warning is one of the important components of supply chain management.

\section{RS-FWSVM Model}

The RS (Rough Set) theory, introduced by Pawlak [2], is a new mathematical tool to deal with vagueness and uncertainty.

SVM (Support Vector Machine), suggested by Cortes and Vapnik [3], evolves from optimal hyperplane under nonlinearly separable situation. It has special advantages in solving problems of small samples, nonlinearity, and high dimension mode recognition.

\footnotetext{
${ }^{\mathrm{a}}$ Corresponding author : 563354676@qq.com
} 
The capability of fault-tolerance and generalization of RS is poor and it can deal only with quantized data . But this is an advantage of SVM. However, SVM can not single out redundant knowledge, which is the advantage of RS. So the RS-SVM model is proposed with both advantages and disadvantages of RS and SVM by some scholars.

Y. L.Wu [4], et. al. built logistics risk evaluation model based on RS and SVM. They carried on application study combining with examples by identifying and classifying the risk information set.X.L.Zhang [5], et. al. proposed a partner selection model based on RS and SVM.The core point of this model was using rough sets theory to pick out the important attributes, and then SVM was used for customer classification. This method that didn't affect classification performance can reduce the data dimensions and the complexity in classification process.J.F.Wang [6], et. al. presented a evaluation model of RS and SVM. They concluded that the accuracy of RS and SVM model in this article would be improved from $98.6 \%$ to $100 \%$ by comparison with applying the SVM directly.

The literatures mentioned above use RS to find out the features of reduced sets by retaining the core attributes to improve the ability of classification of SVM. But the influence of the importance of attributes on the classification failed to be taken into account. But in many cases, features that are not completely relative or even complete-ly irrelative to the problem in the used data, it may affect the classification performances of SVM [7].

In order to solve this problem, the Rough Set--Feature Weighted Support Vector Machine (RSFWSVM)model is put forward So, it is required to impose different weights to different features.

Let $\mathrm{S}$ is the information system of $\mathrm{RS}$, and $\mathrm{S}=(\mathrm{U}, \mathrm{A}, \mathrm{V}, \mathrm{F}), \mathrm{P} \subseteq \mathrm{A}$, $\mathrm{U} /$ ind $(\mathrm{P})=\left\{\mathrm{X}_{1}, \mathrm{X}_{2}, \mathrm{X}_{3}, \ldots, \mathrm{X}_{\mathrm{n}}\right\}$, the information quantity [8] of $\mathrm{P}$ is

$$
\mathrm{I}(\mathrm{P})=\sum_{\mathrm{i}=1}^{\mathrm{n}} p\left(\mathrm{X}_{\mathrm{i}}\right) p\left(\mathrm{X}_{\mathrm{i}}^{\mathrm{c}}\right)=\sum_{\mathrm{i}=1}^{\mathrm{n}} \frac{\left|\mathrm{X}_{\mathrm{i}}\right|}{|\mathrm{U}|}\left[1-\frac{\left|\mathrm{X}_{\mathrm{i}}\right|}{|\mathrm{U}|}\right]=1-\frac{1}{|\mathrm{U}|^{2}} \sum_{\mathrm{i}=1}^{\mathrm{n}}\left|\mathrm{X}_{\mathrm{i}}\right|^{2}
$$

The $|\mathrm{X}|$ indicates the base of $\mathrm{X},{ }^{\left|\mathrm{X}_{\mathrm{i}}\right|} / \mathrm{U} \mid$ is the probability of the equivalence class $\mathrm{X}_{\mathrm{i}}$ in $\mathrm{U}$.

The importance of attribute $\mathrm{a}(\mathrm{a} \subseteq \mathrm{A})$ in $\mathrm{A}$ is

$$
\operatorname{Sig}_{A-\{a\}}(\mathrm{a})=\mathrm{I}(\mathrm{A})-\mathrm{I}(\mathrm{A}-\{\mathrm{a}\})
$$

The SVM that bases on feature weighted kernel function is called FW-SVM [8].Feature weighted kernel function $K_{P}$ is defined as

$$
k_{\mathrm{p}}\left(x_{i}, x_{j}\right)=k\left(x_{i}^{\mathrm{T}} \mathrm{P}, x_{j}^{\mathrm{T}} \mathrm{P}\right)
$$

The $\mathrm{P}=\operatorname{diag}\left(\mathrm{W}_{1}, \mathrm{~W}_{2}, \ldots, \mathrm{W}_{\mathrm{n}}\right)$ is the matrix of a linear transformation, also known as feature weighted matrix. Then FWSVM classification model is

$$
\left\{\begin{array}{c}
\max \sum_{i=1}^{1} a_{i}-\frac{1}{2} \sum_{i=1}^{1} \sum_{j=1}^{1} \alpha_{i} \alpha_{j} y_{i} y_{j} \mathrm{k}\left(x_{i}{ }^{\mathrm{T}} \mathrm{P}, x_{j}{ }^{\mathrm{T}} \mathrm{P}\right) \\
\text { s.t } \quad 0 \leq a_{i} \leq C, i=1, \cdots, 1 \\
\sum_{i=1}^{1} a_{i} y_{i}=0
\end{array}\right.
$$

It's decision function is 


$$
f(x)=\operatorname{sgn}\left(\sum_{i=1}^{1} a_{i} y_{i} \mathrm{k}\left(x_{i}{ }^{\mathrm{T}} \mathrm{P}, x^{\mathrm{T}} \mathrm{P}\right)+b\right)
$$

\section{Crisis early warning of the quality of supply chain based on RS- FWSVM}

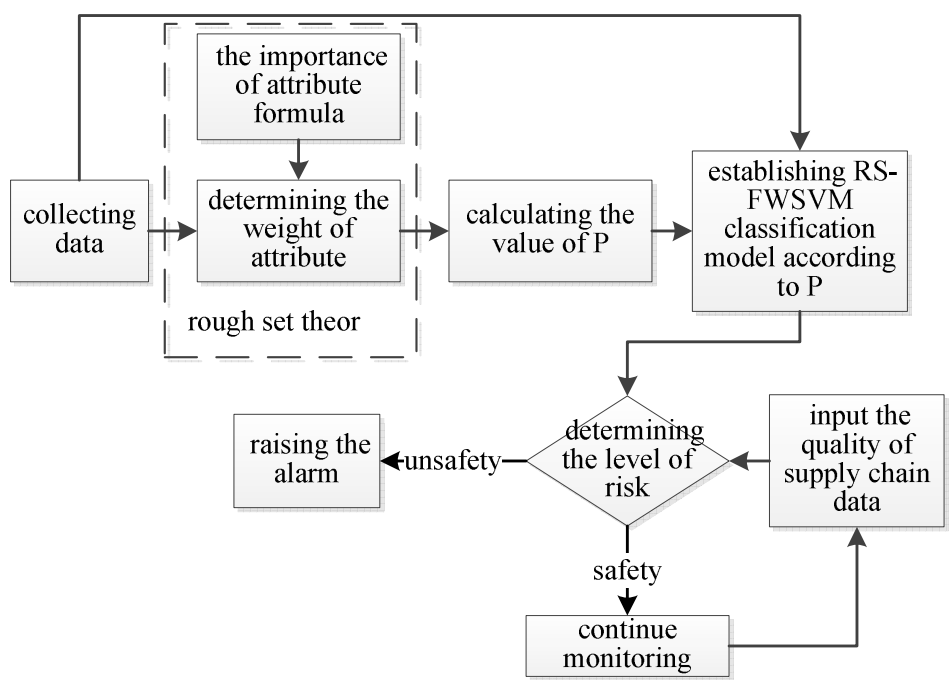

Figure 1. The application process of the crises early warning of the quality of supply chain

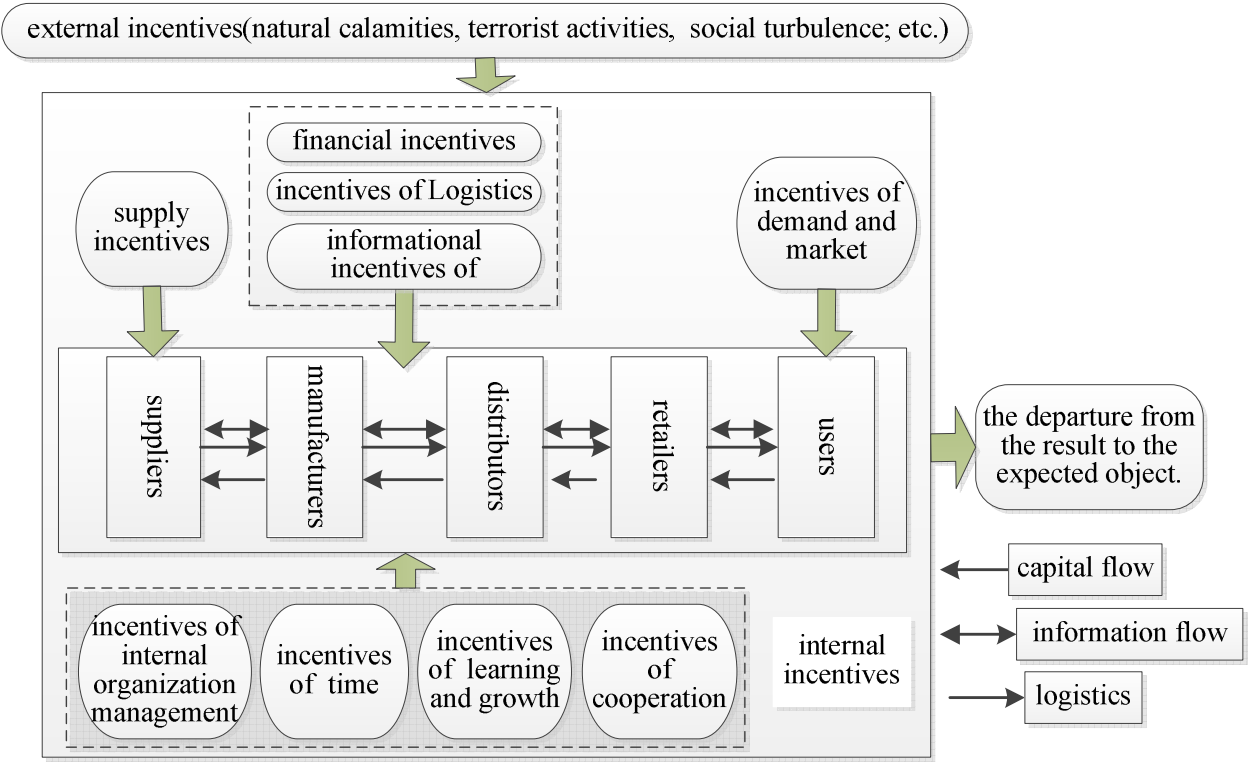

Figure 2. The schematic of incentives of the crises of the quality of supply chain.

The application process of RS-FWSVM in crisis early warning of the quality of supply chain is shown in Fig. 1. Firstly, designing questionnaire according to the index system for the crisis early warning of the quality of supply chain and collecting the data. Secondly, determining the weight of indicators using with the rough set theory and the computation formula of the importance of attribute, and 
obtaining the value of P. Finally, establishing RS-FWSVM classification model according to the collected data and P.

As long as relevant data of the supply chain to be assessed are collected, the crises level of it can be known with the model. If the output is safety, the system will keep monitoring the quality of supply chain, whereas an alarm is raised. Risky supply chain must take action.

\subsection{The Incentives of the crisis of the quality of supply chain and the evaluation index analysis}

The incentives of the crises of the quality of supply chain are the most di-rect reason for supply chain crises. From the source of the crises, which can be grouped into external and internal incentives (Figure 2).

According to the incentives for the crises, relevant references and the investigation in the

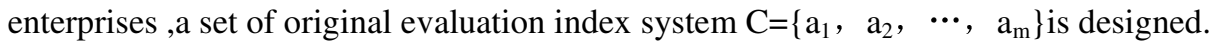

\subsection{Data collection}

This investigation altogether provides questionnaire 110, the actual recovery of 86 copies, of which 84 valid questionnaires, for an effective questionnaire returns-ratio is $76.4 \%$. Data from the questionnaires is collected and analyzed.

\subsection{Weight determination with rough set theory}

Taking data collected in 84 questionnaires as sample, the weights of indicators of the crises of the quality of supply chain is determined by equation 2 (see Table 1 ).

TABLE 1. the weights and means of indicators of the crises of the quality of supply chain

\begin{tabular}{|c|c|c|c|c|}
\hline The Incentives of the Crisis & No. & Indicators & $\operatorname{Sig}_{\mathrm{A}-\left\{\mathrm{a}_{\mathrm{i}}\right\}}\left(\mathrm{a}_{\mathrm{i}}\right)$ & Means \\
\hline \multirow{4}{*}{ external incentives } & a1 & nature disaster & 0.00765 & 3.11 \\
\hline & a2 & macro-economic situation & 0.00510 & 3.76 \\
\hline & a3 & $\begin{array}{l}\text { political stability and government } \\
\text { intervention }\end{array}$ & 0.00538 & 3.5 \\
\hline & a4 & the impact degree of industry & 0.00538 & 3.75 \\
\hline \multirow{6}{*}{ financial incentives } & a5 & turnover of inventory & 0.01694 & 3.87 \\
\hline & $\mathrm{a} 6$ & turnover of account receivable & 0.01204 & 3.7 \\
\hline & a7 & return on equity & 0.01204 & 3.59 \\
\hline & a8 & sales growth & 0.01286 & 3.47 \\
\hline & a9 & quick ratio & 0.01204 & 3.93 \\
\hline & a10 & asset-liability ratio & 0.01286 & 3.31 \\
\hline \multirow{3}{*}{ informational incentives of } & a11 & $\begin{array}{l}\text { the timely information transfer rate } \\
\text { among node enterprises }\end{array}$ & 0.05591 & 3.2 \\
\hline & a12 & $\begin{array}{l}\text { the accurately information transfer rate } \\
\text { among node enterprises }\end{array}$ & 0.0351 & 3.1 \\
\hline & a13 & $\begin{array}{l}\text { the frequency of informational } \\
\text { communication among node enterprises }\end{array}$ & 0.02489 & 3.3 \\
\hline \multirow{3}{*}{ incentives of logistics } & a14 & not strictly inventory control & 0.03920 & 3.63 \\
\hline & a15 & risk in transit & 0.01857 & 3.3 \\
\hline & a16 & order disposal failure & 0.02224 & 2.91 \\
\hline \multirow{3}{*}{ supply incentives } & a17 & the suppliers's on time delivery(OTD) & 0.01061 & 2.8 \\
\hline & a18 & the suppliers's quality of products & 0.01673 & 2.8 \\
\hline & a19 & key suppliers's bankruptcy and losses & 0.03428 & 3.17 \\
\hline
\end{tabular}




\begin{tabular}{|c|c|c|c|c|}
\hline The Incentives of the Crisis & No. & Indicators & $\operatorname{Sig}_{A-\left\{a_{i}\right\}}\left(a_{i}\right)$ & Means \\
\hline \multirow{5}{*}{$\begin{array}{l}\text { incentives of internal } \\
\text { organization management }\end{array}$} & a20 & the supply chain structure rationality & 0.00530 & 3.51 \\
\hline & a21 & the supply chain structure stability & 0.00708 & 3.61 \\
\hline & a22 & $\begin{array}{l}\text { the influence and control ability of the } \\
\text { core enterprise }\end{array}$ & 0.00326 & 3.11 \\
\hline & a23 & $\begin{array}{l}\text { emergency response system of supply- } \\
\text { chain risk }\end{array}$ & 0.01326 & 3.47 \\
\hline & a24 & overall labour productivity & 0.00208 & 3.37 \\
\hline \multirow{2}{*}{ incentives of time } & a25 & processing time of customer complaint & 0.02000 & 2.84 \\
\hline & a26 & customer response time & 0.01715 & 3.21 \\
\hline \multirow{2}{*}{$\begin{array}{l}\text { incentives of learning and } \\
\text { growth }\end{array}$} & a27 & income ratio of new product(service) & 0.04488 & 3.53 \\
\hline & a28 & training expenditures ratio & 0.02325 & 4.27 \\
\hline \multirow{4}{*}{ incentives of cooperation } & a29 & $\begin{array}{l}\text { the equitable degree of the value } \\
\text { distribution among node enterprises }\end{array}$ & 0.03960 & 3.49 \\
\hline & a30 & the coordination of supply chain culture & 0.01674 & 3.46 \\
\hline & a31 & $\begin{array}{l}\text { strategic alignment among node } \\
\text { enterprises }\end{array}$ & 0.01143 & 3.41 \\
\hline & a32 & the coordination among node enterprises & 0.02245 & 3.23 \\
\hline \multirow{5}{*}{$\begin{array}{l}\text { incentives of demand and } \\
\text { market }\end{array}$} & a33 & core enterprise's market share & 0.00408 & 3.4 \\
\hline & a34 & core enterprise's customer satisfaction & 0.00735 & 3.19 \\
\hline & $\mathrm{a} 35$ & customer-keeping ratio & 0.01959 & 3.1 \\
\hline & a36 & inexactly market forecast & 0.00571 & 3.27 \\
\hline & a37 & perfect order fill rate & 0.00571 & 2.91 \\
\hline
\end{tabular}

\subsection{The construction of the crisis early warning of the quality of supply chain based on RS-FWSVM model}

A method of multi-class classification based on FWSVM is put forward. Then FWSVM classifiers are used to conduct classification on crisis level of the quality of supply chain. Where I means safety, $\Pi$ means mildly early-warning, III means moderately early-warning and IV means heavy earlywarning.First, Classifier 1 can divide the data into two groups: I IIand III IV, then Classifier 2 sets III and IV apart from each other, at last, Classifier 2 sets I and II apart from each other(see Fig.3).

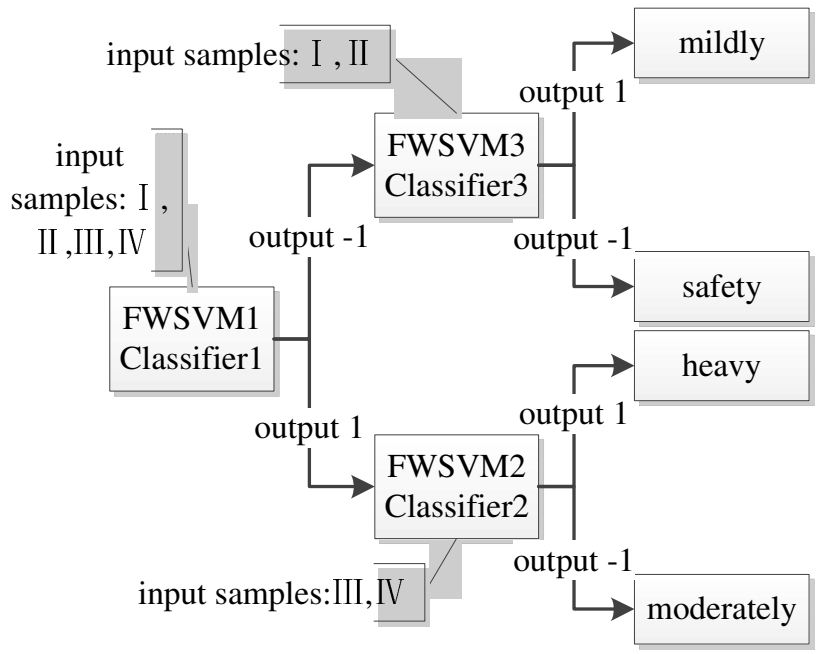

Figure 3. the multi-class classification based on FWSVM. 
63 training samples and 21 test samples are used to the FWSVM1 Classifier 1. The LIBSVM software is also used to classify the samples. The information about the FWSVM1and SVM1, as shown in Fig.4 and Fig.5.

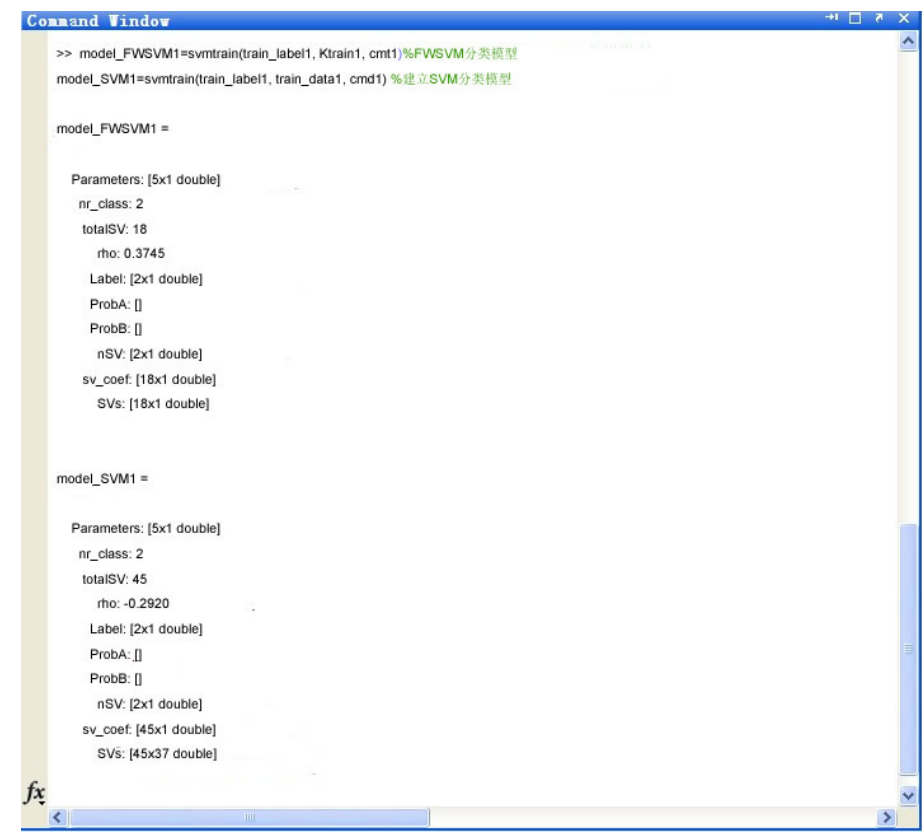

Figure.4 The parameter information about FWSVM1and SVM1

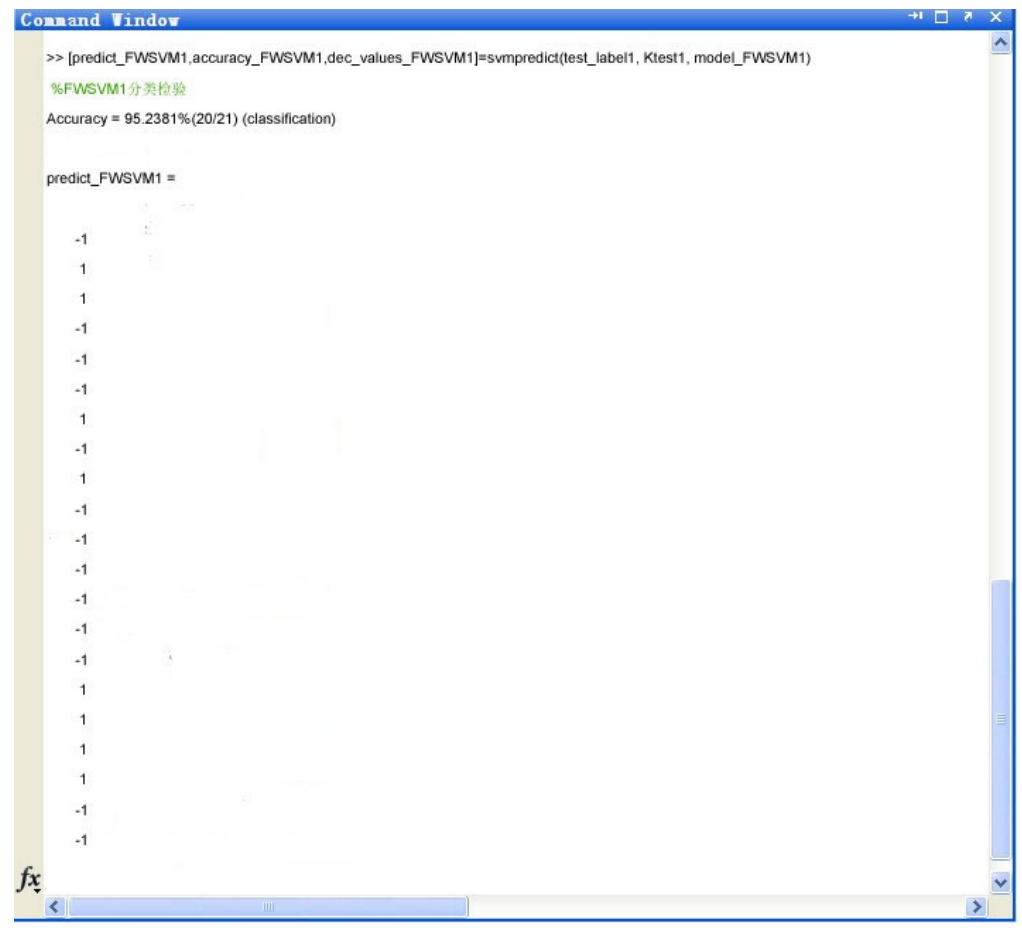

Figure.5 The prediction of FWSVM1

Similarly, additional information about FWSVM and SVM can be calculated. Table 2 is a comparison table of FWSVM and SVM. 
Table 2. Comparison table of FWSVM and SVM.

\begin{tabular}{|c|c|c|c|c|c|c|c|c|}
\hline Classifier & & Actual & C-SVM & classificat & \begin{tabular}{l|l} 
n & C-SVM
\end{tabular} & FWSVM & Classifica & on FWSVM \\
\hline & Samples & Crisis Level & Output & $\begin{array}{l}\text { accuracy } \\
\text { C-SVM }\end{array}$ & 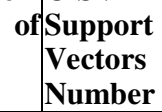 & Output & $\begin{array}{l}\text { Accuracy } \\
\text { FWSVM }\end{array}$ & $\begin{array}{l}\text { of Support } \\
\text { Vectors } \\
\text { Number }\end{array}$ \\
\hline classifier 1 & $\begin{array}{l}\mathrm{sc} 2, \mathrm{sc} 5, \mathrm{sc} 6, \mathrm{sc} \\
4, \mathrm{sc} 7, \mathrm{sc} 8, \mathrm{sc} 1 \\
0, \mathrm{sc} 12, \mathrm{sc} 31, \mathrm{~s} \\
\mathrm{c} 33, \mathrm{sc} 38, \mathrm{sc} 39 \\
, \mathrm{sc} 42, \mathrm{sc} 46, \mathrm{sc} \\
53, \mathrm{sc} 56, \mathrm{sc} 58, \\
\mathrm{sc} 59, \mathrm{sc} 61, \mathrm{sc} 6 \\
2, \mathrm{sc} 63\end{array}$ & \begin{tabular}{|l|} 
\\
II, IV, III, I, \\
I, I, III, II, \\
III, II, I, II, \\
I, II, I, II, \\
III, IV, III, \\
II, II
\end{tabular} & $\begin{array}{l}-1,1,1,-1,-1,- \\
1,1,1,1, \\
1,-1,-1,1,-1,- \\
1,1,1,1 \\
1,-1,-1\end{array}$ & $80.95 \%$ & 45 & $\begin{array}{l}-1,1,1,- \\
1,-1,- \\
1,1,-1,1,- \\
1,-1,-1,- \\
1,-1,- \\
1,1,1,1,1, \\
-1,-1\end{array}$ & $95.24 \%$ & 18 \\
\hline classifier 2 & $\mid \begin{array}{l}\operatorname{sc} 31, \mathrm{sc} 58, \mathrm{sc} 5 \\
9, \mathrm{sc} 61, \mathrm{sc} 80, \mathrm{~s} \\
\mathrm{c} 81, \mathrm{sc} 84,\end{array}$ & \begin{tabular}{|lll} 
III, & III, & IV \\
III, & III, & IV \\
III & &
\end{tabular} & $\mid \begin{array}{l}-1,1,1,-1,- \\
1,1,-1\end{array}$ & $85.71 \%$ & 21 & $\begin{array}{l}-1,-1,1,- \\
1,-1,1,-1,\end{array}$ & $100 \%$ & 15 \\
\hline classifier 3 & $\begin{array}{l}\mathrm{sc} 33, \mathrm{sc} 38, \mathrm{sc} 3 \\
9, \mathrm{sc} 42, \mathrm{sc} 46, \mathrm{~s} \\
\mathrm{c} 53, \mathrm{sc} 56, \mathrm{sc} 62 \\
\mathrm{sc} 63\end{array}$ & \begin{tabular}{|l|} 
II, I, II, I, II, \\
I, II, II, II, \\
\end{tabular} & $\left\{\begin{array}{l}1,-1,1,-1,-1,- \\
1,1,-1,1\end{array}\right.$ & $77.78 \%$ & 17 & $\begin{array}{l}1,-1,1,- \\
1,-1,- \\
1,1,1,1\end{array}$ & $88.89 \%$ & 13 \\
\hline
\end{tabular}

The predict results suggest that the generalization ability of FWSV is superior to C-SVM. It's forecast accuracy is more accurate and than C-SVM,and the number of support vectors is decreased. This could mean that,by compressing geometric space, it has the performance of distinguishing attribute weight, which can improve it's classification capacity.

\section{An application example on the crisis early warning of the quality of supply chain based on RS-FWSVM}

An automobile industry supply chain , where is marked as A , and a textile business supply chain, where is marked as $\mathrm{B}$, are selected to make some empirical analysis. Through investigation and researchnand according to RS-FWSVM model, then the crisis levelof the quality of supply chain is determined.

Data and information is obtained through conducting a number of high-level interviews with A and B. The final data of evaluating indexes as shown in table 3 .

Table 3. The evaluation data of the quality of supply chain

\begin{tabular}{|c|c|c|c|c|c|c|c|}
\hline Evaluation Indicators & $\mathbf{A}$ & B & $\begin{array}{l}\text { Mean } \\
\text { Value }\end{array}$ & Evaluation Indicators & $\mathbf{A}$ & B & $\begin{array}{l}\text { Mean } \\
\text { Value }\end{array}$ \\
\hline nature disaster & 6 & 2 & 3.11 & $\begin{array}{lll}\text { the supply } & \text { chain } & \text { structure } \\
\text { rationality } & & \\
\end{array}$ & 2 & 6 & 3.51 \\
\hline macro-economic situation & 5 & 4 & 3.76 & the supply chain structure stability & 2 & 1 & 3.61 \\
\hline $\begin{array}{l}\text { political stability and government } \\
\text { intervention }\end{array}$ & 2 & 4 & 3.5 & $\begin{array}{l}\text { the influence and control ability of } \\
\text { the core enterprise }\end{array}$ & 2 & 3 & 3.11 \\
\hline the impact degree of industry & 5 & 4 & 3.75 & $\begin{array}{lll}\text { emergency response } & \text { system of } \\
\text { supply-chain risk }\end{array}$ & 2 & 4 & 3.47 \\
\hline turnover of inventory & 2 & 3 & 3.87 & overall labour productivity & 2 & 4 & 3.37 \\
\hline turnover of account receivable & 2 & 4 & 3.7 & $\begin{array}{l}\text { processing time of customer } \\
\text { complaint }\end{array}$ & 2 & 3 & 2.84 \\
\hline return on equity & 3 & 3 & 3.59 & customer response time & 2 & 3 & 3.21 \\
\hline sales growth & 4 & 3 & 3.47 & $\begin{array}{llll}\begin{array}{l}\text { income ratio } \\
\text { product(service) }\end{array} & \text { of } & \text { new } \\
\end{array}$ & 2 & 3 & 3.53 \\
\hline quick ratio & 3 & 4 & 3.93 & training expenditures ratio & 4 & 6 & 4.27 \\
\hline asset-liability ratio & 5 & 4 & 3.31 & $\begin{array}{l}\text { the equitable degree of the value } \\
\text { distribution among node enterprises }\end{array}$ & 2 & 3 & 3.49 \\
\hline
\end{tabular}




\begin{tabular}{|c|c|c|c|c|c|c|c|}
\hline Evaluation Indicators & $\mathbf{A}$ & B & $\begin{array}{l}\text { Mean } \\
\text { Value } \\
\end{array}$ & Evaluation Indicators & $\mathbf{A}$ & B & $\begin{array}{l}\text { Mean } \\
\text { Value } \\
\end{array}$ \\
\hline $\begin{array}{l}\text { the timely information transfer rate } \\
\text { among node enterprises }\end{array}$ & 1 & 3 & 3.2 & $\begin{array}{l}\text { the coordination of supply chain } \\
\text { culture }\end{array}$ & 2 & 3 & 3.46 \\
\hline $\begin{array}{l}\text { the accurately information transfer } \\
\text { rate among node enterprises }\end{array}$ & 2 & 3 & 3.1 & $\begin{array}{l}\text { strategic alignment among node } \\
\text { enterprises }\end{array}$ & 2 & 4 & 3.41 \\
\hline $\begin{array}{l}\text { the frequency of informational } \\
\text { communication among node } \\
\text { enterprises }\end{array}$ & 2 & 3 & 3.3 & $\begin{array}{l}\text { the coordination among node } \\
\text { enterprises }\end{array}$ & 2 & 3 & 3.23 \\
\hline not strictly inventory control & 2 & 4 & 3.63 & core enterprise's market share & 6 & 3 & 3.4 \\
\hline risk in transit & 2 & 2 & 3.3 & $\begin{array}{ll}\begin{array}{l}\text { core enterprise's } \\
\text { satisfaction }\end{array} & \text { customer } \\
\end{array}$ & 3 & 3 & 3.19 \\
\hline order disposal failure & 2 & 1 & 2.91 & customer-keeping ratio & 3 & 2 & 3.1 \\
\hline $\begin{array}{llll}\text { the suppliers's } & \text { on } & \text { time } \\
\text { delivery(OTD) } & & \\
\end{array}$ & 1 & 4 & 2.8 & inexactly market forecast & 4 & 3 & 3.27 \\
\hline the suppliers's quality of products & 1 & 3 & 2.8 & perfect order fill rate & 3 & 4 & 2.91 \\
\hline $\begin{array}{l}\text { key suppliers's bankruptcy and } \\
\text { losses }\end{array}$ & 1 & 2 & 3.17 & & & & \\
\hline
\end{tabular}

Inputting the data from A and B into FWSVM1 classifier, the output is -1 and 1 respectively, indicating that the crisis level of A is safety or mildly early-warning and B is moderately earlywarning or heavy early-warning. When the data from A fed into the FWSVM3 classifier, the result is 1 , so the quality of A's supply chain in the mild warning state.Then inputting the data from B into FWSVM2 classifier, the output is -1, so company B is moderately early-warning. The management personnel of the company $\mathrm{A}$ and $\mathrm{B}$ confirms that the results are consistent with actual situation, that the method and model has a certain practicality and feasibility.

According to the former research on preventing and controlling the crisis of the quality of the supply chain, A should adopt measures to focus in the incentives, paying close attention to deviate from normal levels of early warning indicators. B should take measure to monitor and prevent crisis, to monitor crisis incentives, and take corresponding measures to reduce crisis level of the quality of the supply chain.

Although the crisis level of the quality of the supply chain of B company is not high, can not rule out the individual indicators in a high position, such as the timely information transfer rate among node enterprises, not strictly inventory control, order disposal failure, training expenditures ratio and other indicators. They should be promptly and efficiently controlled by the preventive measures.Otherwise, it will lead to supply risks and damages the quality of the supply chain. Which will bring a huge economic loss to these supply chain enterprises. B company can establish an information sharing platform with suppliers to strengthen the communication among supply chain members, and heighten operation efficiency.

At the same time, supply chain enterprises can establish the information system to record the root cause of the crisis and propose solutions. We can effectively avoid the occurrence of the supply chain quality crisis by settitng up the mechanism of preventing, pre-alarming pre-controlling of crisis. The crisis can't be avoided but can be controlled. Effective crisis prevention can reduce the possible risks. Positive crisis reaction can minimize the loss the crisis may cause.

\section{Conclusion}

RS-FWSVM model is put forward based on the analysis of the advantages and disadvantages of the RS and SVM, and the application flow of this model in the crisis early warning of the quality of the supply chain is studied.The reduced index system of the quality of the supply chain and index weights are obtained based on the rough set, Which simplifying the sample space under the condition of good recognition capability of samples. The improved method takes into account the differences resulting 
from the classification of indexes and gives different weights to them. It is in conformity with authentic situations.

\section{Acknowledgement}

This paper is supported by young and middle-aged teachers education scientific research project in fujian province(No.JAS160713) and project at the university level(No. FWX15012) .

\section{References}

1. X.D. Tang, The strategy analysis of the bullwhip effect in product delivery in the supply chain, China Economist, 5, 46-47 (2010)

2. Z. Pawlak, Rough sets, International Journal of Computer and Information Sciences, 11, 341-356 (1982)

3. C. Cortes and V. Vapnik, Support Vector net-works, Machine Learning, 20, 273-297 (1995)

4. Y.L. Wu, M.L. Liu, and X.Q. Li, A research on risk evaluation of express logistics service based on RSSVM, Logistics Sci-Tech, 37, 11-14 (2014)

5. X.L. Zhang, D.P. Wang, and X.Z. Zhao, Dynamic supply chain partner selection research based on RS and SVM, Mathematics in Practice and Theory, 44, 1-6 (2014)

6. J.F. Wang, X.Y. Sheng, X.Q. Zhai, and L.J. Feng, Capability evaluation of coal mine disaster emergency logistics based on rough set and support vector machine, Safety in Coal Mines, 45, 237-239 (2014)

7. B. Sun, S.J. Song, and C. Wu, A new algorithm of support vector machine based on weighted feature, in Proc. 8th Conf. International Conference on Machine Learning and Cybernetics, Baoding, China, 1616-1620 (2009)

8. W.X. Zhang and G.F. Fang, Uncertain decision-making based on rough set, Beijing, China: Tsinghua University Press, 23 (2006) 